\title{
Oral Health Status in Sickle Cell Anemia Subjects.
}

\author{
Dr. Surekha Rathod ${ }^{1}$, Dr. Rucha Brahmankar ${ }^{2}$ \\ ${ }^{I}$ (Professor, Dept. of Periodontics, VSPM Dental College and Research Centre, Nagpur, India) \\ ${ }^{2}$ (P.G student, Dept. of Periodontics, VSPM Dental College and Research Centre, Nagpur, India)
}

\begin{abstract}
Sickle cell disease is a vascular disorder characterized by chronic, ongoing organ damage that is punctuated by episodes of acutely painful vascular complications. ${ }^{1}$ It is the most common genetic blood disorder in the United States, with about 2000 infants being identified through routine blood screenings annually, and an estimated 104,000-138,000 affected individuals living in the United States. Approximately 0.3\%-1.3\% of African American are affected by Sickle Cell Diseases (SCD). ${ }^{3}$

The aim of this paper is to present oral health status of patients with SCD.

A total of 200 subjects of both sexes in the age group 18-40 years were included in this study. The subjects were examined and the following indices were recorded -

- Oral hygiene index - Simplified (OHI-S).

- Probing depths $(P D)$.

- Clinical Attachment Levels (CAL).

- Gingival Index - Loe and Sillness.

- Turesky Gillmore Glickman Modification of the Quigley Hein Plaque Index. (1970)

- DMFT index.

- Sickle Cell Disease Severity Index.

A total of 1478 patients were screened of which 200 subjects were found to be diagnosed with SCD by electrophoresis. The study thus, included 200 subjects (111 females \& 89 males) diagnosed with Sickle Cell Disease in the age group of 18-40 years.

The probing pocket depths (PPD) were measured in millimeters. $36 \%$ had PPD in the range of $2-4 \mathrm{~mm}, 48 \%$ had $P P D$ in the range of 4-6mm while $16 \%$ had PPD of more than $6 \mathrm{~mm}$.

Similar results were obtained for the Clinical Attachment Levels (CAL). $29.5 \%$ subjects had CAL 2-4mm, $44.5 \%$ had $4-6 \mathrm{~mm} \& 26 \%$ had CAL $6 \mathrm{~mm}$ \& above.

We can thus conclude that although oral health is not a priority for patients with $S C D$, it is supported by increased plaque accumulation. Because of the chronic anemic state of the patients with $S C D$, they should be encouraged to pay strict attention to oral hygiene instructions and practice.
\end{abstract}

Keywords - Chronic, genetic, oral, sickle cell disease, vascular.

\section{INTRODUCTION}

Since the development of Microscope by Jansson in 1950, Sickle cell is the first red cell abnormality that was found out in 1910 by James Herric and since then lots of research has been done in the field of Sickle Cell Anemia all over the world but very little work was done particularly in India.

Sickle Cell Anemia (SCA) is a hereditary anemia, predominantly seen amongst various tribal populations of India. People affected by SCA are frequently misdiagnosed and mistreated. This is not a common iron deficiency (nutritional) anemia. SCA occurs due to inherited abnormal haemoglobin ( $\mathrm{Hb})$ gene, which produce $\mathrm{Hb}-\mathrm{S}$ (Hb-Sickle). The normal human Red Blood Cells (RBCs) carries Hb-A (adult haemoglobin), which helps RBCs in transportation of oxygen in the body. In case of Sickle Cell RBCs, on de-oxygenation (after transferring oxygen to body tissues) because of the presence of $\mathrm{Hb}-\mathrm{S}$ and because of its abnormal characteristic, converts RBCs into rigid-brittle half moon (Sickle) shaped instead of soft round biconcave shape $^{1,3}$.

The rigidity and abnormal shape reduce their ability to be propelled through tiny capillaries \& formation of entangled masses of cells in larger blood vessels. This obstructs the blood flow into organs, producing temporary or permanent organ dysfunction or structural changes and retarded growth. Because of their abnormal shape, the spleen in the body destroys these RBCs, causing enlargement of spleen ${ }^{2}$. Life span of RBC in SCD is less than 30 days instead of 90 to 120 days. Anemia results from the bone marrow's inability to produce enough blood cells to keep pace with the rate of destruction.

The diagnosis of SCA is only possible by carrying out a simple special blood test known as Sickling test on RBCs and further testing by either Hb electrophoresis or by HPLC technique to find out whether the person is heterozygous or homozygous. If either of the parent is having Sickle gene, than the child may be normal or Sickle trait (heterozygous) and if both the parent are having Sickle gene, than the child may be Sickle 
disease (homozygous) or Sickle Trait or Normal ${ }^{3}$. Prevention of Sickle Disease child birth is only possible by marriage counseling and prenatal diagnosis.

Sickle gene is found all over the world, particularly amongst people originated/migrated from Malaria endemic areas of Africa \& Asia. According to one of the hypothesis, it is a natural mutation in Haemoglobin molecule to protect RBCs from malarial parasites by making them a little rigid, so that malarial parasites cannot enter into $\mathrm{RBCs}^{4}$. This is the reason why Sickle Cell gene is present amongst tribal group only, who originated from malaria endemic forest areas ${ }^{5}$.

Sickle cell disease is the commonest genetic disorders in the tribal belt of Central and Southern India. Undivided Madhya Pradesh (Madhya Pradesh and Chhattisgarh) harbors the largest tribal population in India, which is about one fourth of the total tribal population of the country ${ }^{6,7}$. These tribal groups are characterized by their unique socio-cultural and religious practices and follow strict endogamous practice. These tribal populations are stated to be aboriginal population of India. Sickle haemoglobin was first discovered from a tribal population of Nilgiri Hills of South India in 1952. Later, it was reported from the tribal population of Central India i.e. Madhya Pradesh and Chhattisgarh and its surrounding areas falling in the states of Rajasthan, Gujarat, Maharashtra, Andhra Pradesh and Orissa ${ }^{1,8}$. This led to an impression/ belief that sickle haemoglobin is confined to tribal populations/ belt. Later, in some tribal groups like Bhils of Jhabua district, tribal groups of Bastar and Pradhans of district Mandla, Halbas of districts of Rajnandgoan and Durg (unpublished observations), the prevalence rate of sickle haemoglobin have been very high i.e. over 30 percent $^{9}$. The prevalence of sickle haemoglobin from various parts of Madhya Pradesh and Chhattisgarh varied from 15 to 30 percent. It was found that the non-tribal people of $\mathrm{HbS}$ belt especially Scheduled Castes and other Backward class communities have sickle haemoglobin in similar proportion as that of tribals of the area. We have also found prevalence of $\beta$ thalassaemia in various proportions, average 2-4 percent, among the various tribal populations. In some pockets, Scheduled Castes populations e.g. Jharia, Mehra, Dahariya etc. have very high prevalence of sickle haemoglobin i.e. over 30 percent $^{10}$. Co-inheritance of $\beta$-thalassaemia gene alongwith gene for sickle haemoglobin also causes sickle cell disease ${ }^{11}$.

Thus the aim of this paper is to present oral health status of patients with SCD residing in Central India due to its high prevalence in this region.

\section{MATERIALS AND METHODS}

\section{HEADINGS}

It was a randomized, cross sectional study. A total of 200 diagnosed SCD subjects were selected. The study population were selected from the the sickle cell unit at the pediatric ward at Government Medical College, Nagpur. The study was approved by the Institutional Ethics Committee of VSPM's Dental College and Research Centre, Digdoh Hills, Higna Road, Nagpur. A total of 1478 patients were screened of which 200 subjects were found to be diagnosed with SCD by electrophoresis. The inclusion criteria were Patients diagnosed with SCD by electrophoresis in the age group of 18-40 years with permanent dentition and be willing to undergo a clinical examination. The exclusion criteria were pregnant women, patients younger than 18 years of age and patients having mixed/decidous dentition. The subjects were examined and the following indices were be recorded - Oral hygiene index - Simplified (OHI-S), Probing depths (PD), Clinical Attachment Levels (CAL), Gingival Index - Loe and Sillness., Turesky Gillmore Glickman Modification of the Quigley Hein Plaque Index (1970), DMFT index and Sickle Cell Disease Severity Index.3

\section{RESULTS}

A total of 1478 patients were screened of which 200 subjects were found to be diagnosed with SCD by electrophoresis.

Table 1

The study thus, included 200 subjects (111 females \& 89 males) diagnosed with Sickle Cell Disease in the age group of $18-40$ years.

Table 2

The probing pocket depths were measured in millimeters. 36\% had PPD in the range of $2-4 \mathrm{~mm}, 48 \%$ had PPD in the range of $4-6 \mathrm{~mm}$ while $16 \%$ had PPD of more than $6 \mathrm{~mm}$.

Similar results were obtained for the Clinical Attachment Levels (CAL). $29.5 \%$ subjects had CAL 2-4mm, $44.5 \%$ had $4-6 \mathrm{~mm} \& 26 \%$ had CAL $6 \mathrm{~mm} \&$ above.

For the OHI-S, the results showed that majority of the subjects had fair oral hygiene status i.e. $53 \% ; 21.5 \%$ had poor oral hygiene while only $2.5 \%$ had good oral hygiene status.

The results of the Gingival Index showed a greater percentage for the moderate \& severe score with $45.5 \%$ \& $43.5 \%$ respectively while only $11 \%$ belonged to the mild score group.

With respect to Plaque Index, again a higher percentage had a plaque index of 2-4 i.e. 58\%; $21.5 \%$ had plaque index ranging between $4-6 \& 20.5 \%$ had a plaque index of $1-2$. 
The DMFT score in the age group of 18-29 years was 5.62 while 4.36 in the age group of 30-40 years was 4.36 .

\section{Discussion}

Sickle cell disease is a genetic disorder commonly found among people of tropical countries \& transmitted as autosomal recessive trait. Sickle cell disease is a blood condition seen most common in people of African ancestry and in the tribal people of India. There is no cure for SCD is not unknown; however, individuals with SCD had a severe clinical course with acute pain and other complications of the disease along with vaso occlusive crises. Although all the patients included in the study were well maintained, $1 \%$ of the patients had a high severity index.

Prevalence of sickle cell disease in Central India is relatively high.

Maximum prevalence was noted in the Mahaar caste followed by Kunbi's \& Teli's. Also most Mahaars are Boudha by religion, this explains that there are increased cases of SCD among Boudha's compared to Hindus.

SCD is significantly prevalent in Central India, including parts of Maharashtra, Chattisgarh and Madhya Pradesh. The SCD was found to be more prevalent in Mahaar, Kunbi's and Teli's in the descending order. In the present study, 200 patients in the age group of 18-40 years were included these patients had a mixed dentition, plaque \& gingival indices and the Oral Hygiene Index- Simplified was used for the study. Only $2.5 \%$ of the patients had a good oral hygiene score, while $53 \%$ of the patients had a fair score. Also, with regards to probing depths, $36 \%$ patients had a probing depths of $2-4 \mathrm{~mm}, 48 \%$ had $4-6 \mathrm{~mm}$ while $16 \%$ probing depths of $6 \mathrm{~mm}$ and above. However, in accordance with Laurence who carried out a study in African Americans with SCD, the prevalence of caries amongst the study population was significantly high, $12 \%$ had a deft score of $1-3,63 \%$ had a deft score of 4-7 while $25 \%$ had a score of $8-10^{11}$. As already mentioned Laurence had also found a high prevalence of dental caries among African Americans with SCD and a low socioeconomic status. O'Rourke and Hawley, studying patients ages 13-45 years, found no difference between caries prevalence or severity between patients with or without $\mathrm{SCD}^{12}$.

As per P.Famili in a two year investigation of periodontal diseases and Sickle cell Anemia in African Americans, periodontal disease was significantly greater though plaque was not. They concluded that there is higher percentage of periodontal disease involvement among African Americans with Sickle cell anemia ${ }^{13}$.

Crawford has that suggested that SCD is not associated with increased levels of gingivitis and periodontitis in patients with SCD, they did not find any significant difference in alveolar bone loss pattern between patients and controls $^{14}$.

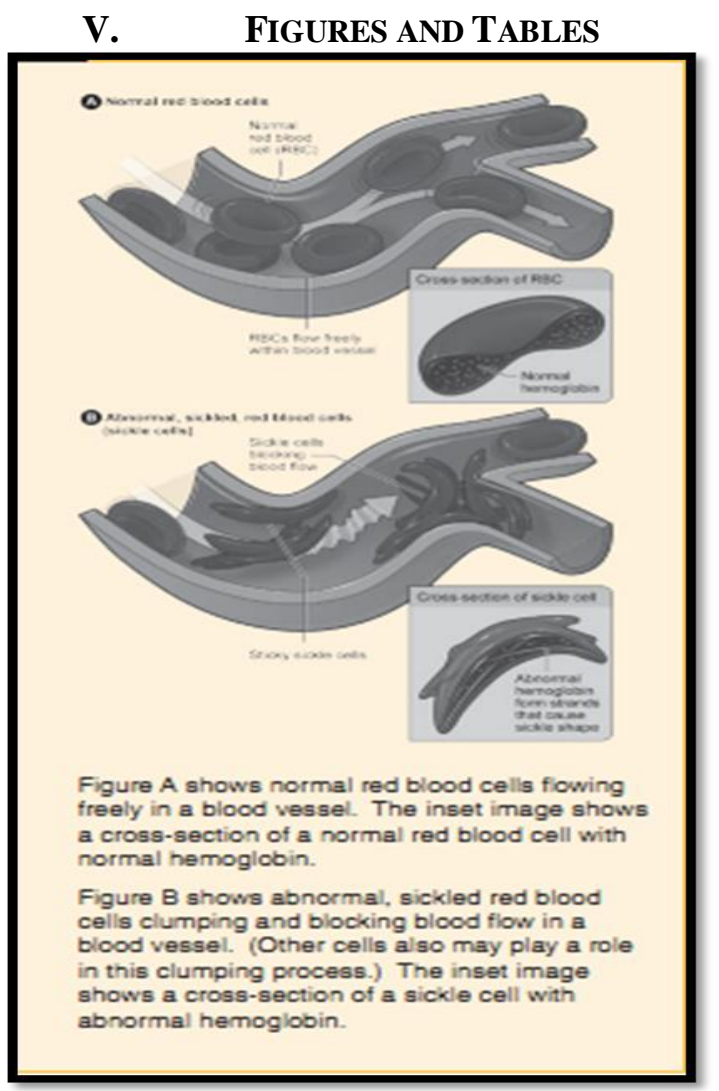

Fig.1 Normal and sickled blood cell. 


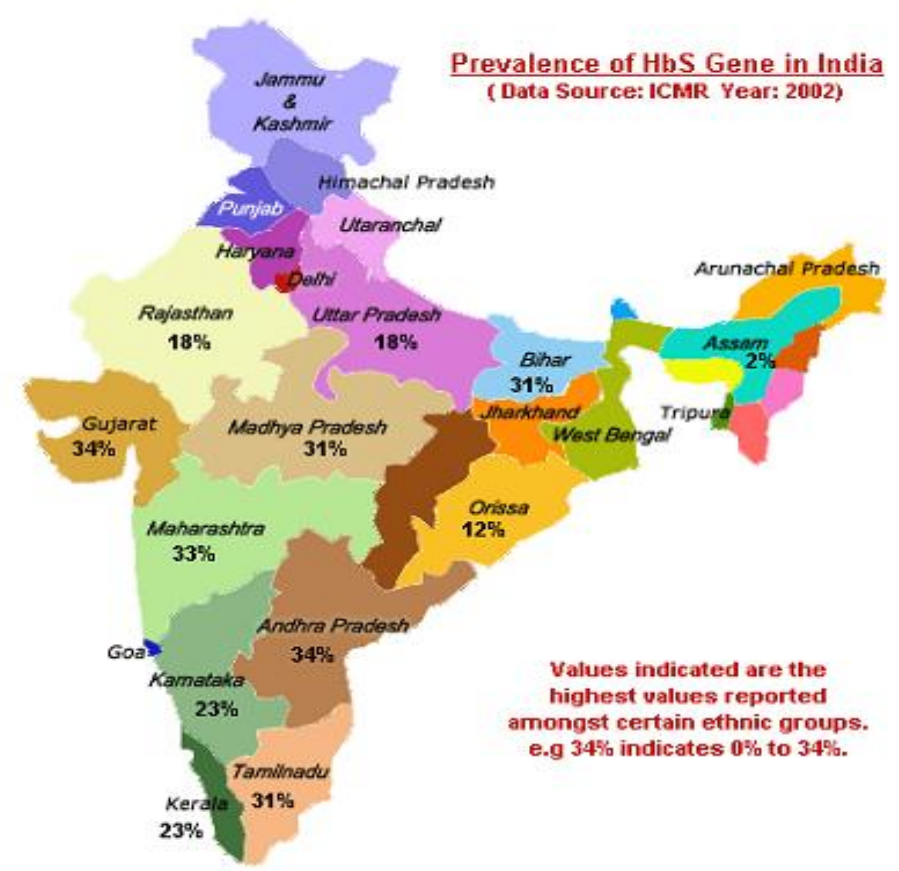

Fig. 2 Prevalence of HbS gene in India.

\begin{tabular}{|l|l|l|l|}
\hline Community & Total cases & $\begin{array}{l}\text { Carriers of sickle } \\
\text { trait }\end{array}$ & Percentage \\
\hline Mahaar & 800 & 138 & $17.25 \%$ \\
\hline Kunbi & 386 & 38 & $9.84 \%$ \\
\hline Teli & 290 & 24 & $8.27 \%$ \\
\hline
\end{tabular}

Table 1: Genotype Distribution Of Patients

\begin{tabular}{|l|l|l|}
\hline Sickle cell severity & No. of subjects & Percentage \\
\hline Low & 145 & $72.5 \%$ \\
\hline Medium & 53 & $26.5 \%$ \\
\hline High & 2 & $1 \%$ \\
\hline
\end{tabular}

Table 2: Sickle cell severity.

\section{CONCLUSION}

We can thus conclude that although oral health is not a priority for patients with SCD, it is supported by increased plaque accumulation. Because of the chronic anemic state of the patients with SCD, they should be encouraged to pay strict attention to oral hygiene instructions and practice. Also, early diagnosis of periodontal disease in sickle cell anemia will show productive \& preventive benefits regarding Sickle cell crisis.

\section{REFERENCES}

[1]. Narsinga Rao BS. Anemia and micronutrient deficiency. Natl Med J India 2003; 16 (Suppl): 46-50.

[2]. O’ Brien RT. Iron burden in sickle cell anemia. J Pediatr 1978; 92: 579-81.

[3]. Cohen A, Schwartz E. Excretion of iron in response to deferoxamine in sickle cell anemia. J Pediatr 1978; 92: 659-62.

[4]. Das PK, Sarangi A, Satapathy M, Palit SK. Iron in sickle cell disease. J Assoc Physicians India 1990; 38 : 847-9.

[5]. Rao NJ, Sur AM. Iron deficiency in sickle cell disease. Acta Paediatr Scand 1980; 69: 337-40.

[6]. Lehmann, H. Cutbush: Sickle cell trait in southern India. Brit. M. J. 1:404, 1952.

[7]. Patel AB, Athavale AM. Sickle cell disease in central India. Indian J Pediatr 2004;71:789-93.

[8]. Agarwal MB. Diagnosis of beta thalassemia trait. Indian Pediatr 1990;27:1124-6.

[9]. Mohanty D, Mukherjee MB. Sickle cell disease in India. Curr Opin Hematol 2002;9:117-22.

[10]. Adekeye, E.O. \& Cornah, J. (1985) Osteomyelitis of the jaws: a review of 141 cases. British Journal of Oral and Maxillofacial Surgery, 23, 24-35.

[11]. Brian Laurence et al. The association between sickle cell disease and dental caries in African Americans. Spec Care Dentist. 2006 ; 26 (3); 95-100.

[12]. P. Famili, C. Miller et al. Two year investigation of periodontal disease and sickle cell anemia. The

[13]. John M Crawford. Periodontal disease in sickle cell disease. J. Periodontol. Mar 1998; 164-9.

[14]. Ramakrishna Y. dental considerations in child suffering from sickle cell disease : A case report. J Indian Soc Pedod prevent dentSept 2007; 140-3. 